\title{
Microvascular Replantation of Distal Digital Amputation in Pregnancy
}

\author{
Dinesh Kadam¹, ${ }^{1,}$ Thrivikrama Padur Tantry ${ }^{2, \odot ~ G a u t h a m ~ J . ~ S h e t t y ~}{ }^{1}$
}

\author{
${ }^{1}$ Department of Plastic and Reconstructive Surgery, A. J. Institute of \\ Medical Sciences and Research Centre, Mangalore, Karnataka, India \\ 2Department of Anesthesiology, A. J. Institute of Medical Sciences \\ and Research Centre, Mangalore, Karnataka, India
}

Indian J Plast Surg 2021;54:375-376.

Successful replantation for amputation injury during pregnancy is very rare, and only a single report has been published so far. ${ }^{1}$ Multiple factors deter salvage attempts concerning maternal and fetal safety. We present a rewarding experience of replantation in full-term pregnancy, followed by an uneventful delivery.

In June 2016, a 29-year woman with 36 weeks of second gravida pregnancy sustained left index finger amputation in the domestic kitchen and arrived within 4 hours of injury from a distance of $100 \mathrm{~km}$. The injury was a sharp oblique
Address for correspondence Gautham J. Shetty MS, MCh, Department of Plastic and Reconstructive Surgery, A. J. Institute of Medical Sciences and Research Centre, Kuntikana, Mangalore, Karnataka, India (e-mail: drgjshetty@yahoo.co.in).

amputation across the distal interphalangeal joint (DIPJ) approximately $5 \mathrm{~mm}$ proximal to the nailbed at the ulnar side through the articular surface of the middle phalanx ( - Fig. 1A, B). The obstetrician's evaluation and ultrasonography ascertained a healthy fetus without premature uterine contractions. After due deliberations, the decision to replant was made.

The considerations for the lengthy procedure besides the safety were as follows: a) optimal maternal position and fetal monitoring, b) type of anesthesia, c) use of heparin

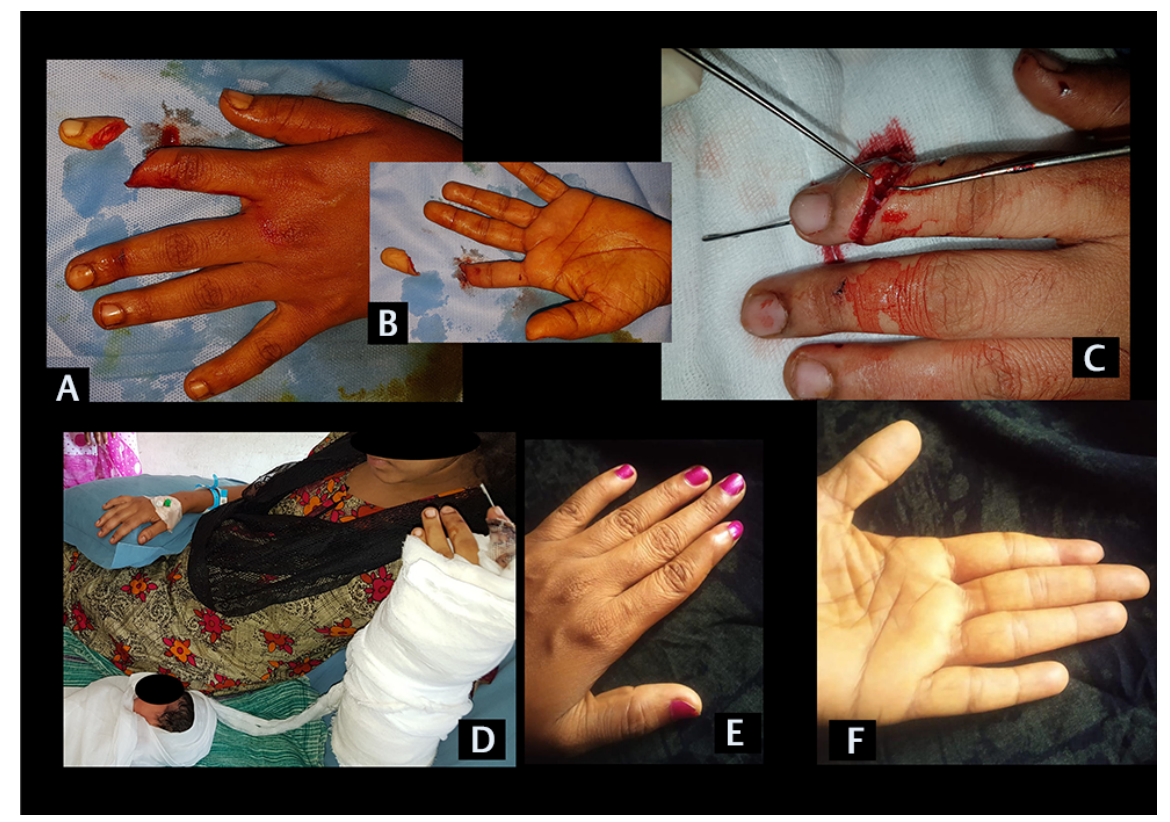

Fig. 1 Sharply cut amputation (A and B), osteosynthesis with K-wire and dorsal venous anastomosis (C), healthy mother, the newborn and replanted digit (D), 4-year postop photographs sent by the patient $(\mathbf{E}, \mathbf{F})$.

published online

September 16, 2021
DOI https://doi.org/

$10.1055 / \mathrm{s}-0041-1736684$ ISSN 0970-0358
(C)2021. Association of Plastic Surgeons of India

This is an open access article published by Thieme under the terms of the Creative Commons Attribution-NonDerivative-NonCommercial-License, permitting copying and reproduction so long as the original work is given appropriate credit. Contents may not be used for commercial purposes, or adapted, remixed, transformed or built upon. (https://creativecommons.org/licenses/by-nc-nd/4.0/).

Thieme Medical and Scientific Publishers Pvt. Ltd. A-12, 2nd Floor, Sector 2, Noida-201301 UP, India 
and other systemic medications, d) postoperative position, e) consent for emergency cesarian section, if needed, and f) dealing with unexpected outcomes and failures. After the wrist block with $1 \%$ lignocaine, she was placed in a left lateral tilted position with a cushioned wedge as mechanical support to the lower back, in order to prevent the gravid uterus from pressing on the pelvic venous system. The surgical procedure lasted for 130 minutes, which included osteosynthesis with 1-mm K-wire without bone shortening, repair of tendons, radial digital artery and nerve, and a dorsal vein with 10-0 nylon suture. No systemic heparin or sedation was used except for a single prophylactic dose of cefotaxime $1 \mathrm{~g}$. Fetal heart was monitored throughout the procedure. The replanted digit maintained good perfusion.

The patient proceeded to normal labor after 3 days and delivered a healthy baby. The postnatal period was uneventful, and both were discharged after 7 days (-Fig. 1D). The K-wire was removed after 6 weeks and advised physiotherapy locally. Four years following the replantation, we contacted her over the phone. She expressed overall satisfaction with the salvage, appearance, sensation, and daily living activities but with a limited range of motion at DIPJ. Although she could not visit the hospital due to logistics, she consented to this publication and sent present photographs ( - Fig. 1E, F). Several favorable factors that yielded positive results included flexor zone-I sharp amputation, regional anesthesia, quicker surgical procedure, minimal systemic medications, and constant fetal surveillance.

There are no specific recommendations available for nonobstetric surgeries in pregnancy. Nevertheless, no emergency procedures should be denied in any trimester, and surgeries in the 3rd trimester are relatively safe, although the potential for preterm delivery exists. ${ }^{2}$. Fetal monitoring during the procedure will guide the secure positioning of the patient. A screening and high suspicion for deep vein thrombosis are necessary for prolonged procedures. ${ }^{2}$ A multidisciplinary approach with swift planning is essential for successful outcome and safety of pregnancy.

\section{Conflict of Interest and Disclosure}

None declared.

\section{References}

1 Haws MJ, Erdmann D, Brown RE. Above-elbow arm replantation during pregnancy. Ann Plast Surg 1996;36(1):93-96

2 Nonobstetric surgery during pregnancy. ACOG Committee Opinion No. 775. American College of Obstetricians and Gynecologists. Obstet Gynecol 2019;133:e285-e286Fig. 1 Sharply cut amputation (A and B), osteosynthesis with $\mathrm{K}$-wire and dorsal venous anastomosis (C), healthy mother, the newborn and replanted digit (D), 4-year postop photographs sent by the patient $(\mathbf{E}, \mathbf{F})$. 